\title{
Experimental Study on the Damage and Deterioration Behaviour of Deep Soft Rock under Water-Rock Interaction
}

\author{
Zenghui Zhao, ${ }^{1,2}$ Hao Liu, ${ }^{1,2}$ Xianzhou Lyu $\left({ }^{3}{ }^{3}\right.$ Lei Wang, ${ }^{4}$ Zhongxi Tian $\mathbb{D}^{5},{ }^{5}$ \\ and Jiecheng Sun ${ }^{6}$ \\ ${ }^{1}$ State Key Laboratory of Mining Disaster Prevention and Control Co-Founded by Shandong Province and the Ministry of Science \\ and Technology, Shandong University of Science and Technology, Qingdao 266590, China \\ ${ }^{2}$ College of Energy and Mining Engineering, Shandong University of Science and Technology, Qingdao 266590, China \\ ${ }^{3}$ College of Earth Science and Engineering, Shandong University of Science and Technology, Qingdao 266590, China \\ ${ }^{4}$ College of Architecture and Civil Engineering, Xi'an University of Science and Technology, Xi'an 710054, China \\ ${ }^{5}$ College of Architecture and Civil Engineering, Liaocheng University, Liaocheng 252000, China \\ ${ }^{6}$ Jinan Rail Transit Group Co., Ltd., Jinan 250101, China
}

Correspondence should be addressed to Xianzhou Lyu; lyuxianzhou0608@sdust.edu.cn

Received 31 July 2020; Accepted 14 August 2021; Published 7 September 2021

Academic Editor: Umberta Tinivella

Copyright (C) 2021 Zenghui Zhao et al. This is an open access article distributed under the Creative Commons Attribution License, which permits unrestricted use, distribution, and reproduction in any medium, provided the original work is properly cited.

\begin{abstract}
The ageing disintegration, the damage, and failure mechanism of water-saturated soft rock are of significance to hazard prevention for deep mining. In this paper, indoor experiments, including disintegration behaviour tests in water, uniaxial compression failure tests of rock samples with different water contents, and variations in the microstructure of mudstone under saturated water contents, were conducted. The investigation results show that the saturated water content of mudstone is $16.96 \%$ and that the rock mass bursts completely after being immersed in water for $72 \mathrm{~h}$. With increasing water content, the uniaxial strength and elastic modulus at the prepeak stage present significant attenuation. However, Poisson's ratio varies little, which indicates that the swelling of cemented mudstone is not obvious when meeting water. In addition, the failure pattern of mudstone changes from overall splitting failure to block fragmentation failure. Due to ion-exchange adsorption and the wedging action of water molecules, the edge of contact between particles changes from staggered to smooth, which leads to the expansion of pores, the loosening of mudstone structures, and a decrease in mechanical strength. Therefore, the diffusion, migration, and particle expansion of illite and other clay minerals in mudstone are the main factors leading to the structural damage and strength reduction of weakly cemented rock under water-rock interactions.
\end{abstract}

\section{Introduction}

Weakly cemented soft rocks are widely distributed in western China, such as Xinjiang, Inner Mongolia, and Ningxia. Due to their poor characteristics of low strength, poor consolidation, easy weathering, and rapid argillization and deterioration after absorbing water, the mechanical properties are unstable. These factors result in severe disturbance, rapid deformation, damage, and disintegration of soft rock during geotechnical construction. Some engineering disasters such as foundation pit collapse, slope sliding, roof bursting, wall caving, and heavy floor heaving often occur, which incur huge economic losses and security threats in the construction of energy engineering, hydraulic engineering, and mining engineering in western areas [1-5]. Thus, it is of great significance to understand and master the damage and disintegration behaviour of weakly cemented soft rock under water-rock interactions to reveal the disaster mechanism and improve the prediction accuracy of engineering disasters.

Water plays an important role in inducing the instability and failure of soft rock. Among soft rocks, weakly cemented mudstone is the most sensitive to water. Such rock is integrated in the dry state, and the structure is compact without obvious fracture. Both engineering practice and laboratory 
tests show that rock disintegration tends to occur during water injections. Soft rock transforms into soil with increasing water content. Under the condition of saturation, some rocks even become silty sand. Thus, the mechanical behaviour of the rock mass obviously deteriorates. At present, many achievements have been made in the study of waterrock interactions at home and abroad, such as the physical and mechanical properties of rock under the water-rock coupling effect [6-8] and the strength softening mechanism of soft rock under water [9-12]. Investigation results show that the dilatancy of rock will gradually decrease to a stable state with an increasing number of water loss cycles and water absorption tests [13-15], and the strength and deformation are seriously affected by the water-rock coupling effect [16-18]. In addition, the effect of water on rock mechanics is time dependent [19-22]. From the perspective of the action mechanism of water on rock [23-25], disintegration due to water swelling and uneven shrinkage of water loss is the main reason that rock softens upon encountering water $[26,27]$. The change in rock structure has a certain influence on the swelling and disintegration characteristics $[28,29]$.

A large number of experiments have been carried out to study water-rock interaction, failure characteristics, and the softening mechanism of rocks with water. However, there are many differences in rock mass properties under different geological conditions. Thus, the above research results cannot accurately explain the macro- and mesomechanical behaviour and degradation characteristics of weakly cemented rock under different water contents. In this paper, mineral composition and mechanical property testing of mudstone were carried out. The damage and disintegration behaviour, strength, and failure characteristics under water-rock interactions were analysed, and the variations in the microscopic structure of mudstone in water immersion were investigated. Finally, the damage and disintegration mechanism of soft rock under water-rock interactions was obtained.

\section{Materials and Methods}

2.1. Rock Samples. Rock samples were obtained by means of deep core drilling in the No. 4 coal mine of Yilin, Xinjiang. To maintain their original state, all collections were sealed immediately. After being transported to the ground, they were sealed again and sealed with wax. From the perspective of the surface and formation mechanism, it is indicated that the typical characteristics of the samples were easy disintegration, low strength, dark grey in colour with a compact structure, and low hammering sound. Moreover, the samples can be carved with fingernail dents. Under extrusion and friction, it is easy to generate longitudinal transfixion cracks, as shown in Figure 1. Thus, the saw blade cutting method was employed instead of the electric saw to avoid generating a transfixion crack. However, scalelike crumbling usually appeared on both sides of the saw blade. Therefore, the success rate of sample preparation was only approximately $35 \%$.

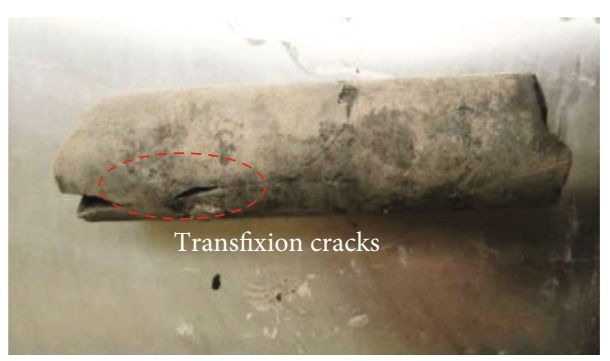

FIgURE 1: Fracture induced by electric saw.

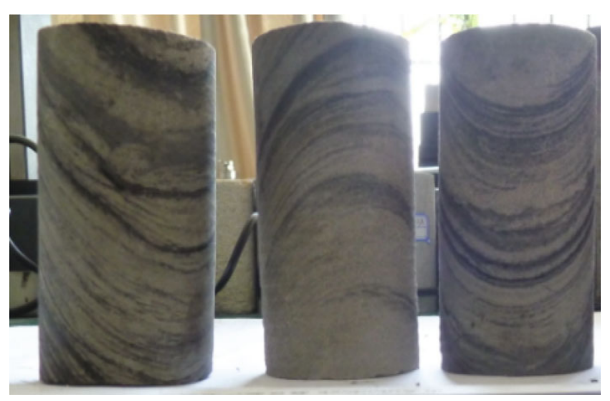

Figure 2: Mudstone samples.

According to the international standard for rock testing, mudstone samples for indoor experiments should be gathered from the same homogeneous rock. All samples were processed into a cylinder with a diameter of $50 \mathrm{~mm}$ and a height of $100 \mathrm{~mm}$. In this test, to control the discreteness of the test results, at least three samples for each moisture content variation were prefabricated for the uniaxial compression test (Figure 2).

2.2. Test Method. To ascertain the softening effect on macroscopic deformation failure characteristics, mechanical properties, and microstructure variations with different water contents, three types of tests were carried out as follows:

(a) Disintegration test of natural mudstone under different immersion times. The observation time of disintegration was set at $10 \mathrm{~h}, 24 \mathrm{~h}, 72 \mathrm{~h}$, and $120 \mathrm{~h}$

(b) Uniaxial compression tests on standard samples selected from five immersion times, $0 \mathrm{~d}, 1 \mathrm{~d}, 2 \mathrm{~d}$, $3 \mathrm{~d}$, and $5 \mathrm{~d}$. The TAW-2000 servo triaxial test system was employed. Axial and radial displacement sensors were set to measure the deformation, as shown in Figure 3. To ensure close contact between the sample and loading devices, a preload of $0.2 \mathrm{kN}$ was applied first. Then, the samples were subjected to axial loading at an axial displacement rate of $0.2 \mathrm{~mm} / \mathrm{min}$ until failure. However, there is some difficulty in pasting resistors on the surface of rock samples, so Poisson's ratio was calculated by the measured radial and circumferential strain

(c) Mineral composition and microstructure variation test of rock samples under natural conditions and saturated immersion conditions by a D8 Advance 


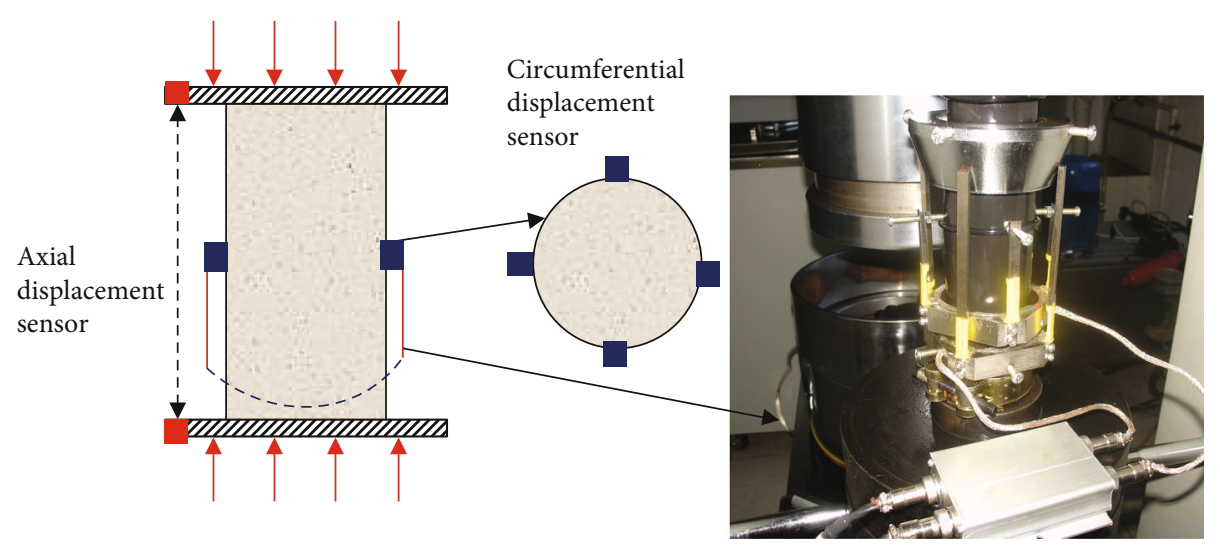

Figure 3: Uniaxial compression test.

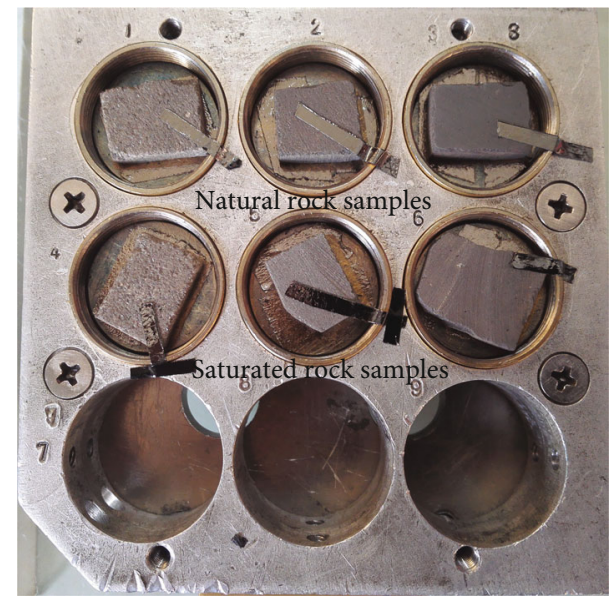

FIGURE 4: Microscopic experiment of rock samples under natural conditions and saturated immersion conditions.

X-ray diffractometer (XRD) and FEI Quanta TM 250 environmental scanning electron microscope (FEM). Rock sample slices are shown in Figure 4. These samples will be used to make mineral composition test samples and electron microscope scanning samples

\section{Results}

3.1. Disintegration Ageing Time Effect. The collapse process of the natural weak cementation mudstones gathered from the field, at room temperature and natural moisture, is shown in Figure 5. Some air bubbles rose from the microfractures after soaking in water for a few minutes, and the container wall was surrounded by layers of bubbles. The sample remained intact within 10 hours, and the colour of the aqueous solution remained essentially unchanged. However, the aqueous solution appeared slightly turbid after being immersed in water for $24 \mathrm{~h}$. Under this condition, microfractures began to develop under the water softening action, and a disintegration phenomenon appeared on the edge of the sample; meanwhile, fragments dropped. As the preexisting crack extended, the samples began to produce new fractures, and an increasing number of bubbles emerged with a buzzing sound. A small amount of black muddy sediment appeared at the bottom of the vessel later. After being immersed in water for $48 \mathrm{~h}$, the sample was completely decomposed and formed initially, and a large amount of sediments appeared at the bottom of the container. According to the preliminary analysis, the black sediments were illites. When the sample was completely immersed in water for 72 hours, the illite quickly and fully combined with the water, and eventually, due to expansion, the sample completely broke and disintegrated.

In addition, if the weakly cemented mudstone close to the saturated state was placed in the room at normal atmospheric temperature, the local surface of the rock presented a scalelike peel off. Finally, global collapse instability occurred because of overall disintegration, as shown in Figure 6.

3.2. Uniaxial Compression Tests. Standard cylindrical samples with different water contents were used to carry out uniaxial compression tests. Table 1 shows the average water content of the five groups of immersed samples.

3.2.1. Immersion Time Effect. Figure 7 shows the stress-strain curves of mudstone with different water contents under uniaxial compression. All of the samples appeared to have rapid destruction and almost no residual bearing capacity after reaching peak strength. The rock sample showed brittle drop characteristics after the peak, the failure process was instantaneously completed, and the strength attenuation was obvious. With increasing water content, the uniaxial compressive strength of the five groups was $8.43 \mathrm{MPa}, 8.05 \mathrm{MPa}$, 6.12 $\mathrm{MPa}, 2.95 \mathrm{MPa}$, and $1.47 \mathrm{MPa}$. The uniaxial compression curves with different water contents were obviously different. When the water content was low, the slope of the curve was steep, so the elastic modulus was larger, and the peak compression strength was larger. The damage of the brittle failure trend was very obvious. However, the curve slopes gradually slowed with increasing water content, and the elastic modulus decreased. Meanwhile, the peak tensile strength decreased obviously. Therefore, brittle failure was gradually weakened, showing ductile failure.

Due to the increase in water content, the internal preexisting fractures in the samples extended, which resulted in 


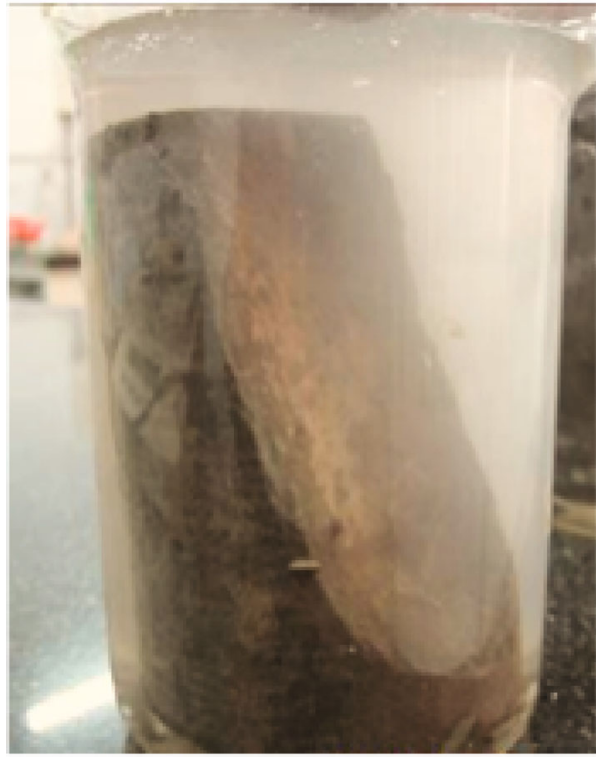

(a) $10 \mathrm{~h}$

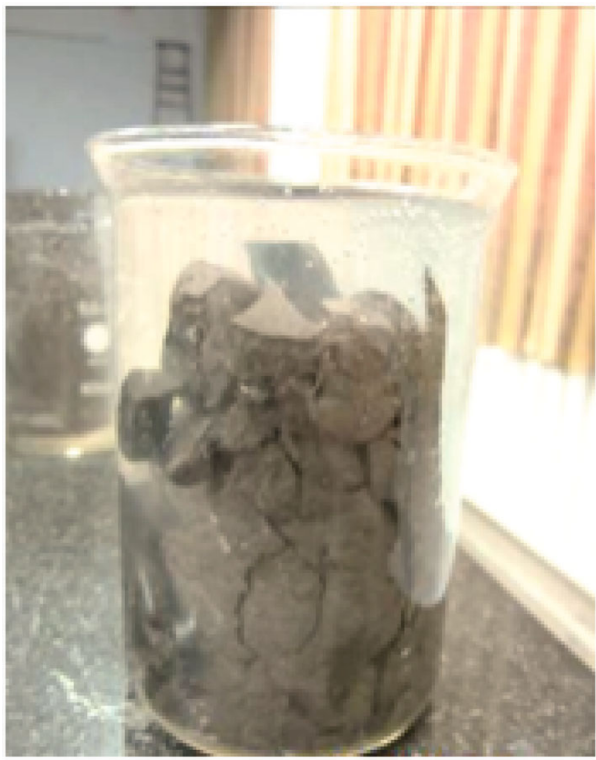

(c) $48 \mathrm{~h}$

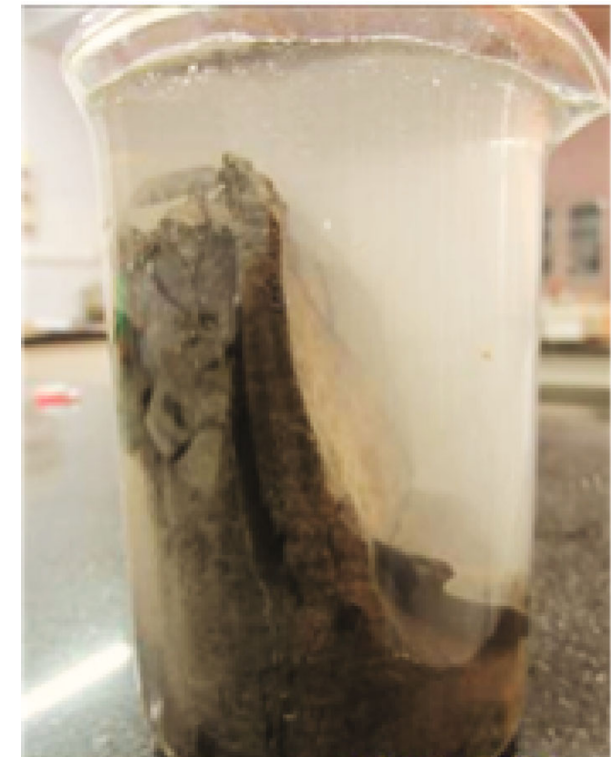

(b) $24 \mathrm{~h}$

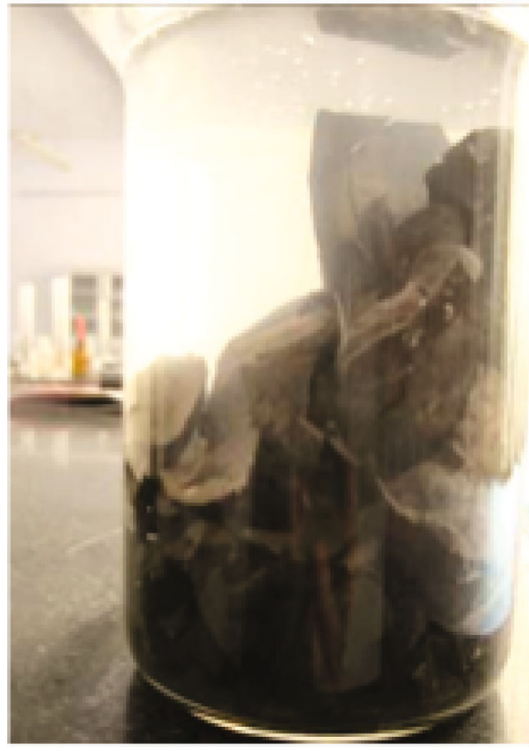

(d) $72 \mathrm{~h}$

FIGURE 5: Disintegration test of weakly cemented mudstone.

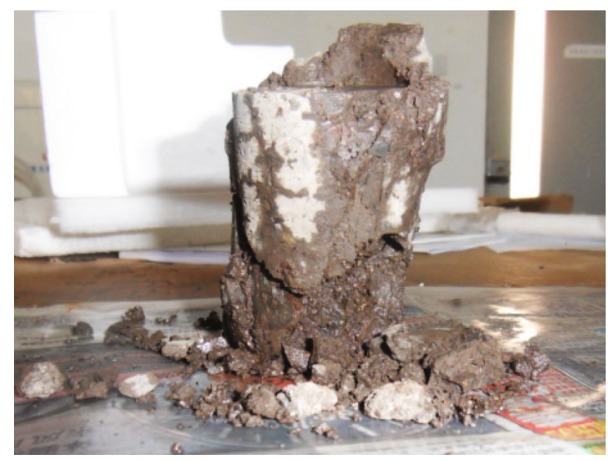

FIgURE 6: Disintegration of the saturated mudstone. partial disintegration. Under this condition, the distribution and density of internal cracks changed significantly, which induced the uniaxial compressive strength of mudstones to a certain degree of dispersity. The stress-strain behaviour of mudstone is extremely sensitive to water, so the corresponding strain at the peak point increased gradually as the water content increased.

The immersion time effect on the reduction in the sheer strength of the mudstone sample is directly reflected through the uniaxial compression strength envelope curve (Figure 8(a)). Different water contents correspond to different immersion times (from 0 to 5 days), and the uniaxial compression strength of the sample decreases gradually. Here, the elastic modulus of samples with different contents 
TABLE 1: Water content for different immersion times.

\begin{tabular}{lccccc}
\hline Immersion time & $0 \mathrm{~d}$ & $1 \mathrm{~d}$ & $2 \mathrm{~d}$ & $3 \mathrm{~d}$ & $5 \mathrm{~d}$ \\
Water content & $3.35 \%$ & $9.43 \%$ & $12.12 \%$ & $15.58 \%$ & $16.18 \%$ \\
\hline
\end{tabular}

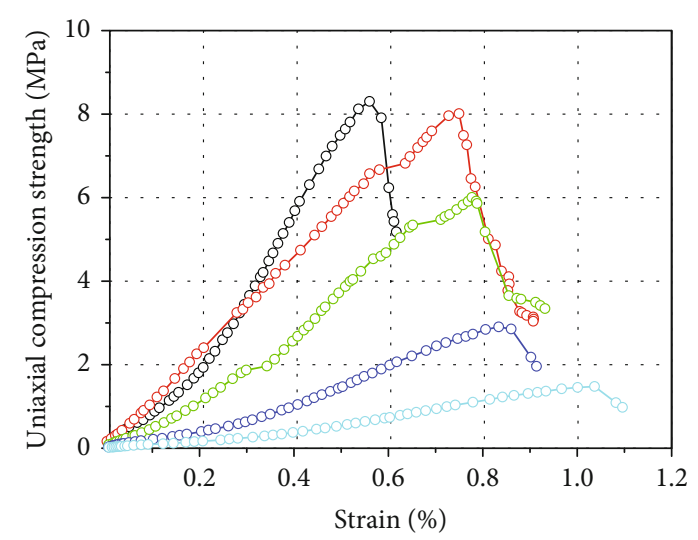

$$
\begin{aligned}
\multimap & \mathrm{w}=3.35 \%(\text { natural condition) } \\
\multimap & \mathrm{w}=9.43 \%(1 \mathrm{~d}) \\
\multimap & \mathrm{w}=16.18 \%(5 \mathrm{~d}) \\
\multimap & \mathrm{w}=15.58 \%(3 \mathrm{~d}) \\
\multimap \mathrm{w} & =12.12 \%(2 \mathrm{~d})
\end{aligned}
$$

FIGURE 7: Stress-strain relations of mudstone samples with different water contents under uniaxial compression.

is calculated by the tangent elastic modulus of the $50 \%$ per cent stage of the peak stress at the postpeak stage of the stress-strain curve. As shown in Figure 8(b), the elastic modulus decreases as the duration of immersion increases.

According to the radial deformation results, the variation in Poisson's ratio is presented in Figure 8(c). The changing tendency reduces first and increases afterward but does not vary sharply. To verify this result, resistance strain gauges were also used to measure axial and lateral deformation. The calculated Poisson's ratio compared with the test has no visible distinction. Due to the lower montmorillonite in the mudstone, water swelling is not obvious. The Poisson's ratio does not significantly change with increasing water content.

The physical parameters of the mudstone changing with water content are fitted by the least square method. The relationship between the uniaxial compression strength and water content is

$$
\sigma_{\mathrm{c}}=8.74-0.074 \exp (0.28 w)
$$

The relation between the elastic modulus and water content is

$$
E=1.87-0.27 \exp (0.11 w)
$$

where $\omega$ is the moisture content of the mudstone, $\sigma_{c}$ is the uniaxial compression strength (units: $\mathrm{MPa}$ ), and $E$ represents the elastic modulus (units: GPa).

3.2.2. Saturation Softening Effect. To assess the softening effect of saturation, the reduction in compression strength with the number of days of saturation is analysed. As the saturation days increase, both the compression strength and elastic modulus show an exponential decrease. As shown in Table 2, both their decline rates slowed down significantly after the third immersion day. According to the characteristics of the attenuation of strength parameters (Figure 9), 3 days of immersion is the critical amount of time for the reduction of compression strength of the rock sample. The test results show that the softening effect of mudstone caused by fissure water is fundamentally expressed through changes in the physical and mechanical properties and internal structures of rocks.

\subsubsection{Damage Forms of Mudstone with Different Water} Contents. It is difficult to obtain integral mudstone samples after compression failure. Thus, we traced the damage form of samples under uniaxial compression, as shown in Figure 9.

From the above diagram, samples in the natural state show splitting failure, which is similar to the initial failure. After being immersed in water for 1 day, some microcracks appeared on the end surface of the sample. However, the main compressive failure form was splitting failure. After being immersed in water for 2 days, microcracks on the surface of the sample tended to expand, and the crack numbers increased without penetration. Meanwhile, a main crack was generated. After immersion in water for 3 days, the microcracks extended, and local denudation occurred at the lower end of the sample. Due to the softening effect of the samples and internal crack propagation, two obvious fracture zones were generated in the rock sample. After 5 days, an obvious crack appeared on the surface of the sample, which caused extensive disintegration.

\section{Microstructure Evolution}

To further reveal the fundamental failure mechanism of weakly cemented mudstone, we tested the mineral composition and microstructure of rock samples by X-ray diffraction (XRD) and scanning electron microscopy (SEM). The interaction between groundwater and rock can change minerals and chemical compositions and decrease the coupling forces between particles.

4.1. Mineral Composition and Microstructure of Mudstone under Natural Conditions. The mineral composition was characterized by X-ray diffraction (XRD), as shown in Figure 10 . The $x$-axis in the $\mathrm{X}$-ray diffraction pattern graph represents the rotation angle; the $y$-axis represents the diffraction intensity. Based on the analysis of the diagram shown in Figure 10(b), the main compositions are quartz, illite, orthoclase, and dickite, with illite accounting for 30.4 percent. Although illite accounts for as high as $30.4 \%$ and is an intermediate mineral between muscovite and kaolinite and montmorillonite, it is not an expansive clay mineral and does not easily expand when placed in water for a long time. There were no mineral swellings, such as kaolinite and montmorillonite. Therefore, the water swelling of the mudstone was not obvious. 


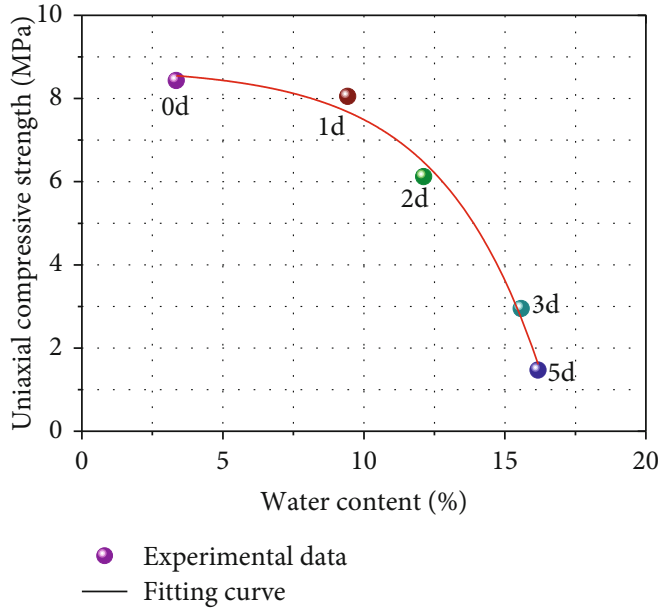

(a) Uniaxial compression strength

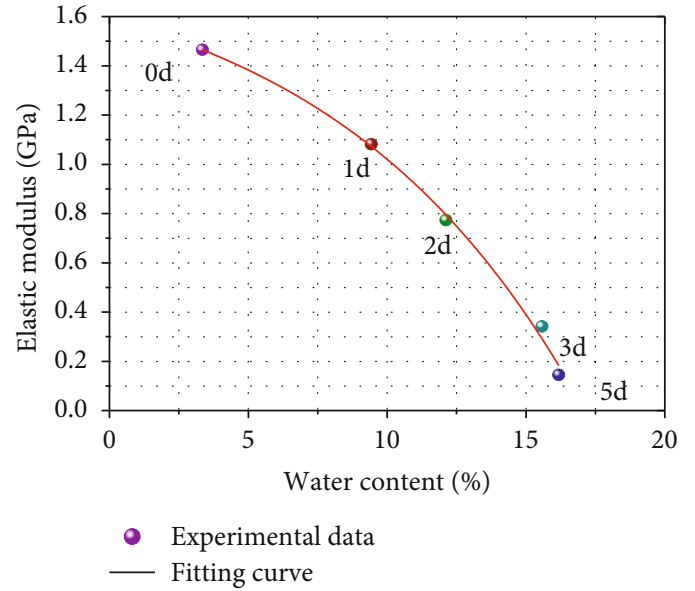

(b) Elastic modulus

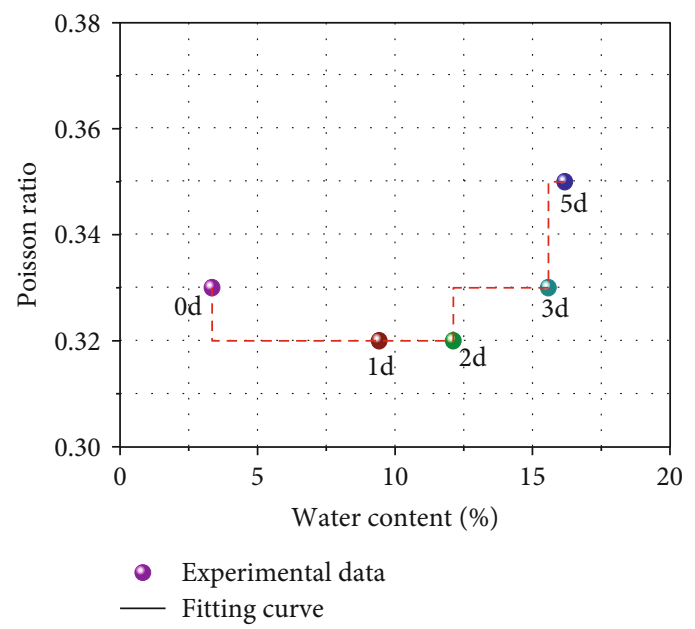

(c) Poisson's ratio

FIGURE 8: Variations in mechanical parameters with different water contents.

TABLE 2: Effect of saturation time on mechanical parameters.

\begin{tabular}{lccc}
\hline No. & $\begin{array}{c}\text { Saturation time } \\
\text { (days) }\end{array}$ & $\begin{array}{c}\text { Uniaxial compression } \\
\text { strength (MPa) }\end{array}$ & $\begin{array}{c}\text { Elastic } \\
\text { modulus (GPa) }\end{array}$ \\
\hline 1 & 1 & 8.43 & 1.46 \\
2 & 2 & 8.05 & 1.08 \\
3 & 3 & 6.12 & 0.77 \\
4 & 5 & 2.95 & 0.34 \\
\hline
\end{tabular}

The microscopic structure of mudstone slices under natural conditions is observed by scanning electron microscopy (SEM). As shown in Figure 11, when the SEM magnification is increased to 300 times, the clay minerals are shown to be closely arranged and oriented, and the pore space is well distributed, which is composed of pores of accumulation bodies. When the SEM magnification was enlarged to 2500 times (Figure 11), the structure dominated in the form of surface-surface and surface-edge contacts, and the edges of mineral granules were irregular zigzag polygons.
4.2. Mineral Composition and Microstructure of Mudstone under Water-Rock Interactions. As found in this X-ray diffraction analysis of rock samples after 5 days of immersion (Figure 12), the diffraction intensity of the clay minerals decreased. This suggests that the original mineral composition changed after five days of immersion.

Compared with the sample under natural conditions, the proportion of illite increased, and the proportion of kaolinite and dickite decreased, as shown in Table 3. The main components of the clay minerals were dominated by illiterate and quartz, followed by orthoclase and dickite. With the increase in illite composition, the connection between grains of mudstone is weakened because of its water absorption and expansion, the strength of the rock is reduced, and the ability to resist deformation is weakened at the macrolevel. Due to the poor water permeability of mudstone, the effect of water-rock interactions is developed, which accelerates the process of clay gouged intercalation.

To determine the inherent mechanism of the strength reduction of mudstone due to water-rock interactions, we carried out SEM tests on samples after 5 days of immersion. As shown in Figure 13, the changes in the crystal edges can 

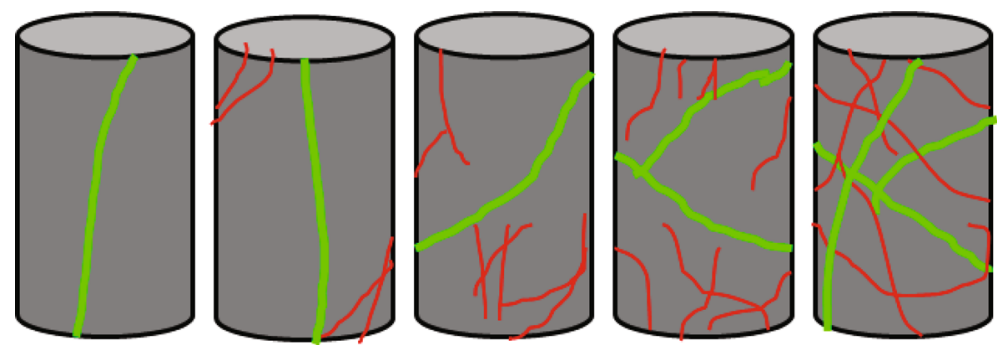

Figure 9: Diagram of the failure pattern with different water contents.

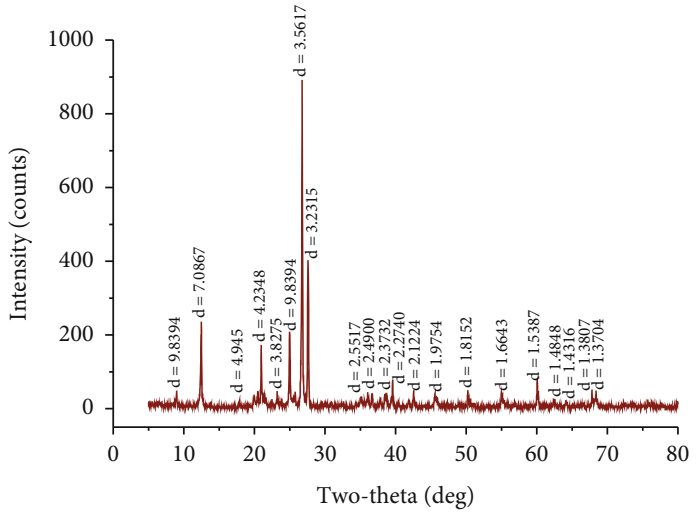

(a) X-ray diffraction

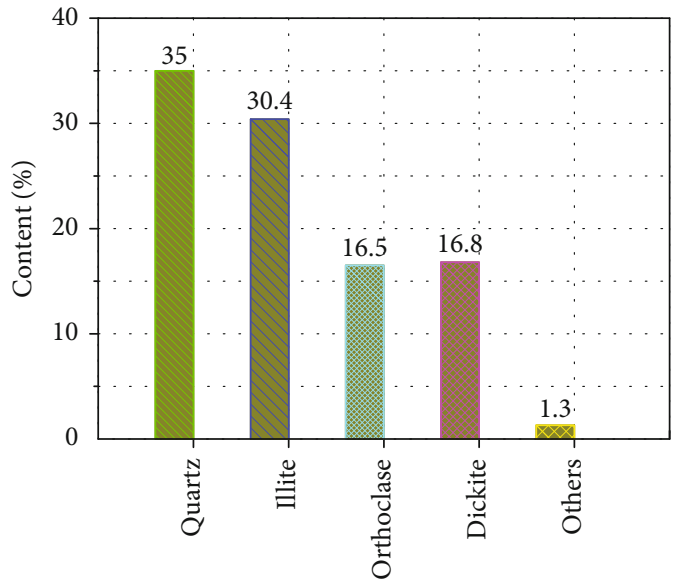

(b) Proportion of mineral composition

FIGURE 10: Mineral components of mudstone and sandstone.

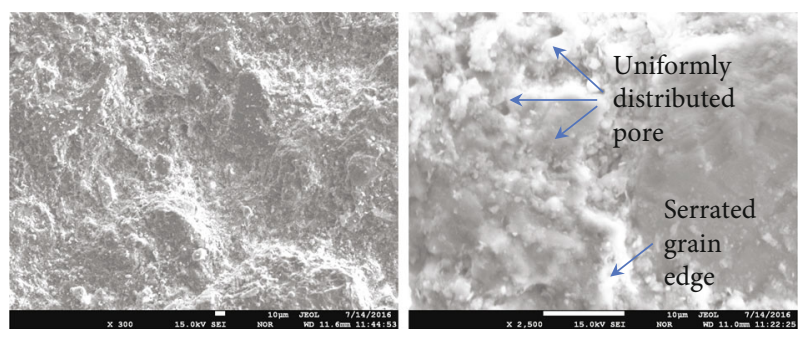

FIGURE 11: Microstructural characteristics of mineral surfaces under natural conditions.

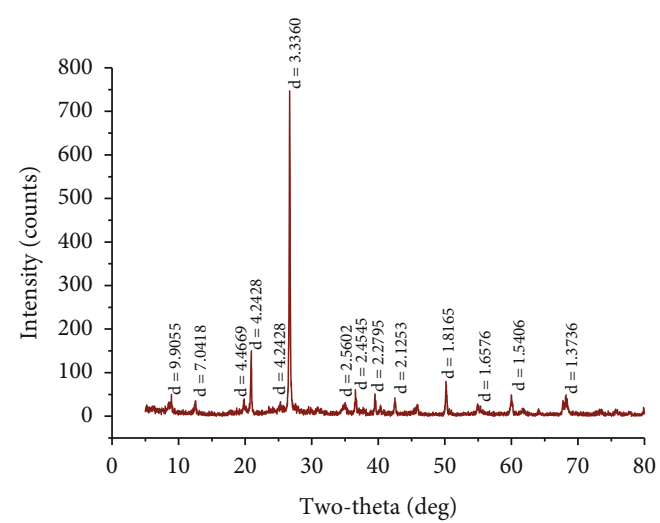

Figure 12: X-ray diffraction of a rock sample after 5 days of immersion. be observed by comparing the clay mineral microstructure with the results under natural conditions. In this test, to exclude unexpected chemical reactions, distilled water was adopted for rock sample immersion.

As the duration of immersion increased, the edges of the crystal grains changed from a clear zigzag shape to a round shape. Compared with Figure 11, the microstructure changes from dense granular to irregular flocculent. The micropores in the clay minerals expanded after water immersion and finally transformed into a mass-like structure. Due to its strong water binding capacity, the cementation force of mineral particles decreased. Thus, a few quartz, orthoclase, and other skeletal particles were peeled off from the surface.

After 5 days of immersion, the clay particles agglomerated into clusters. The particles were mainly connected by the edge, which contributed to the attenuation of the connection between the agglomerates and the clusters. Thus, the pores expanded and were unevenly distributed between the particles.

4.3. Damage Evolution Mechanism of Mudstone. Overall, the damage evolution of mudstone is substantially caused by the decay of the inherent microstructure of the clay minerals. The ion exchange and the water-rock interaction effect on the microstructure of mudstone is the dominant factor of mudstone damage. A comparison between Figures 14(a) and $14(\mathrm{~b})$ indicates that the content of $\mathrm{Al}$ changed little, 
TABLE 3: Comparison of mineral compositions of rock samples under natural conditions and water immersion.

\begin{tabular}{|c|c|c|c|c|c|}
\hline Sample & $\begin{array}{c}\text { Percentage (\%) } \\
\text { Quartz }\end{array}$ & $\begin{array}{l}\text { Percentage (\%) } \\
\text { Illite }\end{array}$ & $\begin{array}{c}\text { Percentage (\%) } \\
\text { Orthoclase }\end{array}$ & $\begin{array}{c}\text { Percentage (\%) } \\
\text { Dickite }\end{array}$ & $\begin{array}{c}\text { Percentage (\%) } \\
\text { Others }\end{array}$ \\
\hline Natural condition & 35 & 30.4 & 16.5 & 16.8 & 1.3 \\
\hline 5 days of immersion & 31 & 35.2 & 14.3 & 15.5 & 4 \\
\hline
\end{tabular}
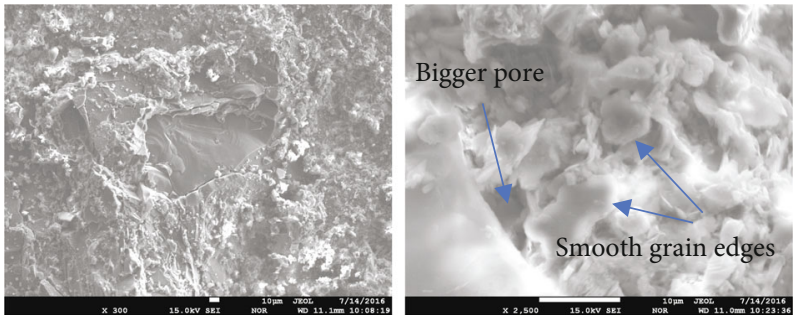

FIgURE 13: Microstructural characteristics of the mineral surface after 5 days of immersion.

while the content of $\mathrm{K}$ decreased rapidly. This means that, during the immersion process, clay minerals hydrolyse through ion exchange reactions. The ideal chemical composition of illite is $\mathrm{K}_{0.75}\left(\mathrm{Al}_{1.75} \mathrm{R}\right)\left[\mathrm{Si}_{3.5} \mathrm{Al}_{0.5} \mathrm{O}_{10}\right](\mathrm{OH})_{2}$, while the molecular formula of montmorillonite is ( $\mathrm{Al}$, $\mathrm{Mg})_{2}\left[\mathrm{Si}_{4} \mathrm{O}_{10}\right](\mathrm{OH})_{2} \cdot \mathrm{nH}_{2} \mathrm{O}$. Thus, illite accounts for a large proportion of mudstone. It is also fully explained that the form of mudstone transverse separation is caused by hydrolysis of illite.

The failure behaviour of weakly cemented soft rock is physics of the earth, geochemistry, etc., and a variety of long-term results of the role of factors. On the one hand, ion exchange decreases the connection between clay particle cements with water immersion, resulting in the loss of connections between clastic particles under the action of gravity. In addition, the volume expansion caused by the water absorption of clay minerals is nonuniform. The nonuniform stress formed at the clay interior enables an increase in micropores, which destroys the internal structure of rock samples gradually and results in the disintegration of rock. On the other hand, the clay minerals of mudstone are dominated by illite, which has strong hydrophobicity. During the immersion process, polarized water molecule layers formed due to the water continuously entering the pores between the flaky particles. Meanwhile, the interlayer water layer formed at the intercrystalline layer of clay minerals when the water infiltrated.

The evolution mechanism mentioned above indicates that water molecules will gradually enter the clay particle pores and granular layers, which induces the volume expansion of the clay minerals and uneven inner stress. Subsequently, ion-exchange adsorption and the wedging action of water molecules will induce softening and degradation of mudstone structures. Finally, due to the chemical action of the aqueous solution on the edge of mudstone particles, the edge of contact between particles changes from staggered to smooth, which leads to the loosening of the mudstone structure and a decrease in mechanical strength.

\section{Discussion}

5.1. Damage Behaviour of Mudstone with the Variation of Water Content. After the mudstone is immersed in water for quite some time, water will enter into the microcracks and pores. Under the action of an external stress field, the seepage stress of water will superpose on the external stress field, producing a force on the rock sample. This mechanical effect is closely related to the water content. The test results show a uniaxial compressive strength of mudstone in the water-saturated state of $1.47 \mathrm{MPa}$ and an elastic modulus of $145 \mathrm{MPa}$, which are $17.4 \%$ and $9.93 \%$ that of the natural state, respectively. Variation in the water content has a remarkable effect on the strength and stiffness parameters of mudstone.

Under the influence of water-rock interactions, the macroreduction in the uniaxial compressive strength of mudstones is closely related to the microscopic mechanism of water chemistry. This is mainly due to the effect of water solution molecules or ions on erosion, dissolution, and exchange of rocks and minerals, which change the composition and structure of rock and rub the lattice of miner while lowering the strength of mudstone.

5.2. Time Effect of Water-Rock Damage. Water plays an important role in the development of internal microcracks through so-called stress corrosion during the deformation of mudstone. The actions include migration and absorption of applied stress, action of the crack surface, and elimination and migration of applied products (black argillaceous sediment). In addition, because of serious argillization of mudstone in water, there is no significant difference in the Poisson's ratio of mudstone between the natural state and saturated state, indicating that the effect of water on rock deformation is isotropic.

According to the test results, the mechanical parameter of mudstone degraded obviously when it met water, and different immersion times resulted in different degrees of deterioration. Therefore, we defined the damage variable of the water-rock interaction of mudstone as

$$
D(t)=1-\frac{\sigma_{c}(t)}{\sigma_{c}(0)},
$$

where $D(t)$ and $\sigma_{c}(t)$ are the damage variable and uniaxial compressive strength after water-rock interaction at time $t$, respectively. $\sigma_{c}(0)$ is the initial value of the uniaxial compressive strength. $D(t)=0$ represents nondamage, and $D(t)$ $=1$ represents complete damage.

The natural uniaxial compressive strength $(8.43 \mathrm{MPa})$ of mudstone is taken as the initial value; then, we can obtain 


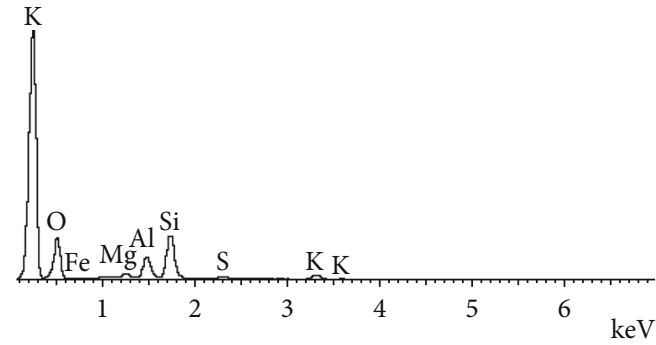

(a) Natural condition

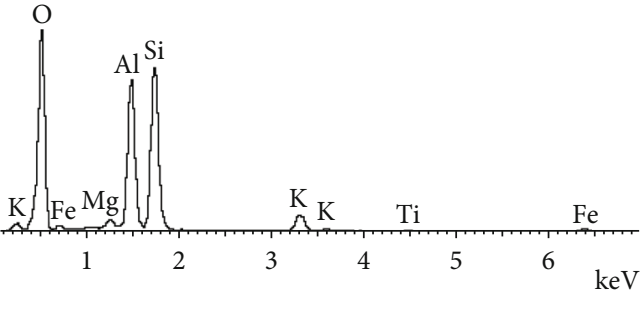

(b) Water immersion

FIGURE 14: X-ray diffraction pattern of mudstone.

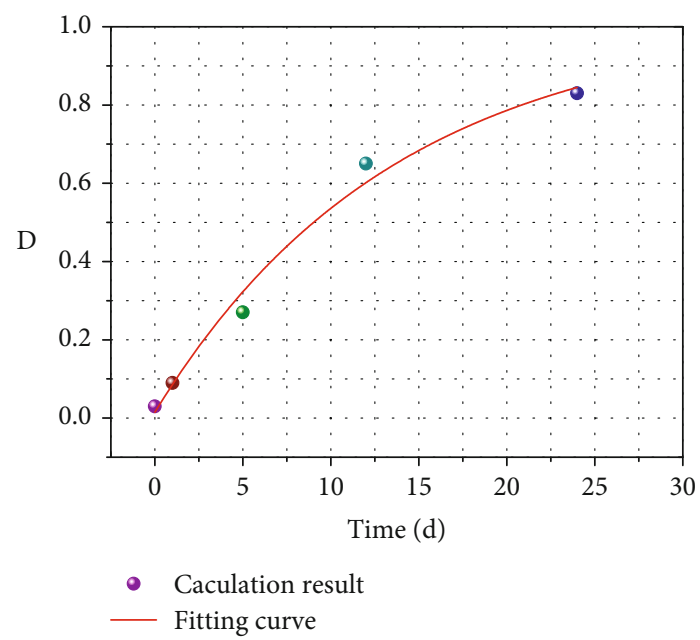

Figure 15: Evolution of the damage variable.

the curve of the damage value of the water-rock interaction variation with immersion time based on the results of the water-rock interaction test, as shown in Figure 15.

According to the least-squares method, the evolution of the water-rock interaction damage variable is fitted as follows:

$$
D(t)=1.017-\exp (-t / 13.63) .
$$

The mechanical effect of water-rock interaction on rock is significant and has a strong time dependence. Let $S_{D}$ be the damage value $d D(t)$ in unit time $(d t)$. Thus, the damage rate can be expressed as

$$
S_{D}=\frac{d D(t)}{d t}=-0.073 \exp (-t / 13.63) .
$$

5.2.1. Relationship between the Failure Behaviour and Microstructure Change of Mudstone. The failure behaviour of mudstone is substantially caused by the decay of the inherent microstructure of the clay minerals. With increasing water immersion time, the pores in the rock mass expand and gradually fill with water. Subsequently, the binding force is reduced due to the counterions escaping from the interlayers, which induces a change in the microstructure structure of soft rock. In addition, due to the softening action of the water solution, the edges of mineral particles become smooth. Thus, the contact between the particles gradually changed to face-edge contact, edge-edge contact from face-face contact, and face-edge contact. The transition process from steady-state surface contact and surface-edge contact to unsteady-state surface-edge contact and edgeedge contact shows that the mineral particles with uniform, good integrity, and orderly arrangement are transformed into a loose, flocculated, and disorderly arrangement, and then, the dense microstructure is destroyed, resulting in the decrease of overall strength and the deterioration of macroscopic strength. In conclusion, the influence of water content on the strength of weakly cemented soft rock is a progressive process from microscopic structural changes to macroscopic mechanical property degradation.

\section{Conclusions}

From the disintegration test, mudstone is determined to be muddy cementation. The mechanical effect of water-rock interaction on mudstone is closely related to the water content. However, they are not simply linear relationships. The deformation and failure process of mudstone are significantly affected by water. The damage under water-rock interaction is significant and time dependent.

It is not enough to consider the mechanical effect of water on mudstone from only the principle of effective stress. Stress corrosion should also be taken into account in such a complex process. In this study, the action of water on the deformation of mudstone is isotropic. Compared with the natural state, Poisson's ratio of samples in the water-saturated state has no significant differences. Therefore, the intramolecular and cemented expansions of clay minerals are the basic mechanisms that lead to structural damage of mudstone under dynamic water conditions.

From the perspective of microscopic testing, the failure mechanics behaviour of mudstone is mainly caused by the physical and chemical interaction of clay minerals in the process of water-rock interaction. With increasing water immersion time, the pores between the particles become larger and unevenly distributed. Thus, the degree of mineral particle cementation is greatly weakened.

The fracture effect and macroscopic strength effect induced by water-rock interaction widely exist in geological disasters such as earthquakes, tectonic fault activity, rock landslides, and rock destruction. Therefore, it is essential to promote experimental study on the effect of water chemistry 
on rock mechanics and fracture mechanics to provide new ideas for the prediction and prevention of offshore geological hazards.

\section{Data Availability}

The data used to support the findings of this study are included within the article.

\section{Conflicts of Interest}

The authors declare that they have no conflicts of interest.

\section{Acknowledgments}

This paper was supported by the National Natural Science Foundation of China (Nos. U1806209, 51774196) and the Scientific research project of Jinan rail transit group Co. Ltd. of China (No. HX2020-B33).

\section{References}

[1] Z. Zhao, W. Wang, L. Wang, and C. Dai, "Compression-shear strength criterion of coal-rock combination model considering interface effect," Tunnelling and Underground Space Technology, vol. 47, no. 47, pp. 193-199, 2015.

[2] Z. H. Zhao, W. Sun, S. J. Chen, D. W. Yin, H. Liu, and B. S. Chen, "Determination of critical criterion of tensile-shear failure in Brazilian disc based on theoretical analysis and mesomacro numerical simulation," Computers and Geotechnics, vol. 134, article 104096, 2021.

[3] Z. Zhao, W. Wang, and X. Gao, "Evolution laws of strength parameters of soft rock at the post-peak considering stiffness degradation," Journal of Zhejiang University SCIENCE A, vol. 15, no. 4, pp. 282-290, 2014.

[4] X. Lyu, Z. Zhao, X. Wang, and W. Wang, "Study on the permeability of weakly cemented sandstones," Geofluids, vol. 2019, no. 14, Article ID 8310128, p. 14, 2019.

[5] Z. Zhao, W. Sun, M. Zhang, X. Gao, and S. Chen, "Fracture mechanical behavior of cracked cantilever roof with large cutting height mining," Shock and Vibration, vol. 2020, no. 10, Article ID 1641382, p. 10, 2020.

[6] Z. Liu, C. Zhou, D. Su, Z. Du, and L. Zhang, "Rheological deformation behavior of soft rocks under combination of compressive pressure and water-softening effects," Geotechnical Testing Journal, vol. 43, no. 3, article 20180342, 2020.

[7] B. Gao, Y. Liu, J. Pan, and Y. Tian, "Detection and analysis of height of water flowing fractured zone in underwater mining," Chinese Journal of Rock Mechanics \& Engineering, vol. 33, no. 2, pp. 3384-3390, 2014.

[8] Z. Erguler and R. Ulusay, "Water-induced variations in mechanical properties of clay-bearing rocks," International Journal of Rock Mechanics and Mining Sciences, vol. 46, no. 2, pp. 355-370, 2009.

[9] D. Qin, X. Wang, D. Wang, and X. Chen, "Study on surrounding rock-bearing structure and associated control mechanism of deep soft rock roadway under dynamic pressure," Sustainability, vol. 2019, no. 11, article 11071892, 2019.

[10] J. Jiang, W. Xiang, J. Rohn, W. Zeng, and M. Schleier, "Research on water-rock (soil) interaction by dynamic tracing method for Huangtupo landslide, Three Gorges Reservoir, PR
China," Environmental Earth Sciences, vol. 74, no. 1, pp. 557571, 2015.

[11] J. Yu, W. Yao, K. Duan, X. Liu, and Y. Zhu, "Experimental study and discrete element method modeling of compression and permeability behaviors of weakly anisotropic sandstones," International Journal of Rock Mechanics and Mining Sciences, vol. 134, article 104437, 2021.

[12] D. Agustawijaya, "The uniaxial compressive strength of soft rock," Civil Engineering Dimension, vol. 9, no. 1, pp. 9-14, 2007.

[13] M. Duda and J. Renner, "The weakening effect of water on the brittle failure strength of sandstone," Geophysical Journal International, vol. 192, no. 3, pp. 1091-1108, 2013.

[14] M. Çelik, H. Akbulut, and A. Ergül, "Water absorption process effect on strength of ayazini tuff, such as the uniaxial compressive strength (ucs), flexural strength and freeze and thaw effect," Environmental Earth Sciences, vol. 71, no. 9, pp. 4247-4259, 2014.

[15] L. Guo, H. Bin, Y. Bin, and G. Zhang, "Contrast study on forecast of shear strength of unsaturated soil using soil water characteristic curve," Journal of Engineering Geology, vol. 21, no. 6, pp. 849-856, 2013.

[16] J. Sedano and S. Vanapalli, "Experimental investigation of the relationship between the critical state shear strength of unsaturated soils and the soil-water characteristic curve," International Journal of Geotechnical Engineering, vol. 5, no. 1, pp. 1-8, 2013.

[17] U. Aqtash and P. Bandini, "Prediction of unsaturated shear strength of an adobe soil from the soil-water characteristic curve," Construction \& Building Materials, vol. 2015, no. 98, pp. 892-899, 2015.

[18] Z. Han and S. Vanapalli, "Stiffness and shear strength of unsaturated soils in relation to soil-water characteristic curve," Géotechnique., vol. 66, no. 8, pp. 627-647, 2016.

[19] D. Ivars, "Water inflow into excavations in fractured rock-a three-dimensional hydro- mechanical numerical study," International Journal of Rock Mechanics and Mining Sciences, vol. 43, no. 5, pp. 705-725, 2006.

[20] M. Bidgoli and L. Jing, "Water pressure effects on strength and deformability of fractured rocks under low confining pressures," Rock Mechanics \& Rock Engineering, vol. 48, no. 3, pp. 971-985, 2015.

[21] Y. Liu, C. Liu, Y. Kang, D. Wang, and D. Ye, "Experimental research on creep properties of limestone under fluid-solid coupling," Environmental Earth Sciences, vol. 73, no. 11, pp. 7011-7018, 2015.

[22] J. Yu, G. Liu, Y. Cai, J. Zhou, S. Liu, and B. Tu, “Time-Dependent Deformation Mechanism for Swelling Soft-Rock Tunnels in Coal Mines and Its Mathematical Deductio," International Journal of Geomechanics, vol. 20, no. 3, article 04019186, 2020.

[23] B. Bohloli and C. Pater, "Experimental study on hydraulic fracturing of soft rocks: influence of fluid rheology and confining stress," Journal of Petroleum Science and Engineering, vol. 53, no. 1-2, pp. 1-12, 2006.

[24] D. Zu, C. Chen, X. Feng, and Y. Zhang, "Strength failure and crack coalescence behavior of sandstone containing single pre-cut fissure under coupled stress, fluid flow and changing chemical environment," Journal of Central South University, vol. 21, no. 3, pp. 1176-1183, 2014.

[25] L. Wong, V. Maruvanchery, and G. Liu, "Water effects on rock strength and stiffness degradation," Acta Geotechnica, vol. 11, no. 4, pp. 1-25, 2015. 
[26] Ö. Aydan, "The inference of physico-mechanical properties of soft rocks and the evaluation of the effect of water content and weathering on their mechanical properties from needle penetration tests," Journal of the Agricultural Chemical Society of Japan, vol. 29, no. 5, pp. 707-711, 2012.

[27] Á. Török and B. Vásárhelyi, "The influence of fabric and water content on selected rock mechanical parameters of travertine, examples from Hungary," Engineering Geology, vol. 115, no. 3, pp. 237-245, 2013.

[28] R. Yan, Q. Tong, X. Cui, and M. Na, "Experimental study on the water-physical properties of swelling rock and release rules of swelling potential energy," Nonferrous Metals: Mining Section, vol. 66, no. 4, pp. 63-66, 2014.

[29] D. Zhang, A. Chen, R. Su, H. Duan, and G. Liu, "Effect of hydrothermal environment on distintegration of different purple parent rocks," Acta Pedologica Sinica, vol. 50, no. 4, pp. 643-651, 2013. 